\section{O conhecimento etnoecológico dos pescadores yudjá, Terra Indígena Paquiçamba, Volta Grande do Rio} Xingu, PA* Ethnoecological knowledge of Yudjá
fisherman, Indigenous Land Paquiçamba,
Volta Grande of Xingu River, Pará

\author{
Jaime Ribeiro Carvalho Júnior** \\ Maria de Jesus da Conceição Fonseca*** \\ André Ribeiro de Santana**** \\ Luiza Nakayama*****
}

Resumo: Com objetivo de descrever conhecimentos dos pescadores yudjá, sobre peixes de importância comercial e/ou subsistência, realizamos entrevistas com os pescadores e acompanhamos a sua lida diária. Verificamos que o conjunto de informações etnoecológicas que os Yudjá possuem é dinâmico e envolve pesquisa, experimentação, observação, raciocínio, especulação e intuição. Além da transmissão cultural entre gerações, muitos saberes, dizeres e fazeres aperfeiçoamse em uma mesma geração, por meio das conversas e outras interações cotidianas. O patrimônio teórico-prático compartilhado pelos pescadores yudjá serviu como subsídio para elaboração do projeto Piracema: a pesca e a piscicultura itinerante para os índios Yudjá, que contribuirá para desenvolver uma ação educativa numa perspectiva dialógica, com pescadores da comunidade.

Palavras-chave: Juruna; Peixe; Etnobiologia indígena.

Abstract: We carried out interviews with fishermen and accompanied their daily work to describe the knowledge of the Yudja fishermen with regard to important subsistence and/or commercial fish species. We verified that the ethnoecological information that the Yudja fishermen possess is dynamic and involves research, experimentation, observation, logic, speculation, and intuition. Apart from the transmission of culture between generations, knowledge, sayings and practices are perfected within a generation through conversations or other daily interactions. The heritage of theory-practice shared by fishermen could serve as a model for the "Piracema Project: fish
* Este artigo é parte da tese de doutorado do primeiro autor. ** Doutorando na pós-graduação em Ciência Animal (PPGCA-UFPA), pesquisador do LABIO/UFPA/CENJA/Instituto Mar Dulce. Em 2008, publicou o capítulo de livro: Diagnóstico, Tendências e Perspectivas para o Desenvolvimento da Pesca Ornamental in Diagnóstico da Pesca e da Aquicultura do Estado do Pará. Belém: Governo do Estado do Pará - SEPAq e participou do relatório técnico-científico do Estudo de Impacto AmbientalRelatório de Impacto Ambiental (EIA-RIMA) Belo Monte. E-mail: jaimejr@ufpa.br

*** Orientadora no Programa de Mestrado em Educação da UEPA, fundadora e coordenadora do Núcleo de Estudos em Educação Científica, Ambiental e Práticas Sociais-Necaps. E-mail: mariadejesusff@yahoo.com.br

**** Doutorando na pósgraduação em Educação em Ciências e Matemáticas (PPGECM-UFPA), membro da Sala Verde Pororoca: espaço socioambiental Paulo Freire (Sala Verde - UFPA); Professor da SEDUC-PA. E-mail: mestredeo@yahoo.com.br

***** Orientadora no PPGCA e no PPGECM, ambos da UFPA; coordenadora da Sala Verde Pororoca - UFPA. E-mail: lunaka@ufpa.br
Tellus, ano 11, n. 21, p. 123-147, jul./dez. 2011

Campo Grande, MS 
and itinerant pisciculture for the Yudjá" and in the promotion of other diverse educational activities.

Key words: Juruna; Fish; Indigenous ethnobiology.

\section{Os Yudjá de Paquiçamba}

Os Juruna se autodenominam Yudjá, que, de acordo com o linguista Fargetti (1997), significa "dono do rio", traduzindo a imagem de exímios canoeiros e excelentes pescadores.

O termo Juruna significa "boca preta" (yuru - "boca", una - "preta") e se refere a uma linha vertical preta, de 2 a $4 \mathrm{~cm}$ de largura, que desce do centro do rosto, a partir da raiz dos cabelos, passando pelo nariz, contornando a boca e terminando no queixo: essa forma de expressão era característica dos Juruna até a metade do século XIX (Saraiva, 2005). Os Yudjá são referidos por índios de outras etnias e por não indígenas, como Juruna; no presente trabalho, trataremos essa etnia como eles se autodenominam.

Os Yudjá da Terra Indígena (TI) Paquiçamba habitam a margem esquerda do rio Xingu, entre os igarapés Paraíso e Mangueira, na região que sofre uma acentuada sinuosidade, formando a chamada Volta Grande do Xingu (VGX), a qual faz parte da "Área de Influência Direta" e "Área Diretamente Afetada", do projeto "Usina Hidrelétrico (UHE) Belo Monte". Esse trecho da VGX pertence ao município de Vitória do Xingu, situado no estado do Pará (Saraiva, 2007a; Vieira et al., 2009).

A TI Paquiçamba, com superfície de 4.348 hectares, é constituída por três núcleos residenciais: o primeiro deles, considerado o núcleo residencial principal, possui eletricidade, água encanada, posto de saúde, escola, estrutura para caixa d'água, placas de energia solar, campo de futebol, casa de professor e 10 moradias indígenas habitadas; o segundo é composto pelas moradias localizadas à margem do Furo do Barracão, totalizando quatro residências fixas; no Furo Seco, encontra-se o terceiro núcleo residencial, com três famílias residentes, sendo uma não-indígena (Vieira et al., 2009).

Atualmente, os Yudjá da TI Paquiçamba são pequenos produtores que vivem da agricultura familiar e da coleta de produtos não madeireiros, destacando-se como pescadores e caçadores. Beneficiam a mandioca para produção e comércio da farinha, coletam e vendem castanhas, pescam para o consumo e comércio. Têm se dedicado à atividade profissional da pesca de peixes ornamentais, devido à ampliação de mercado em nível regional, nacional e internacional (Saraiva, 2007a, 2007b; Vieira et al., 2009).

Os índios yudjá da TI Paquiçamba não se diferenciam socioculturalmente dos habitantes ribeirinhos do médio rio Xingu, ou seja, todos se expressam unicamente em português, não usam vestimentas típicas e adornos da cultura 
ancestral no dia-a-dia. As transformações pelas quais os Yudjá foram submetidos, desde as conquistas pelos portugueses até os dias atuais, contribuíram para sua dispersão, para o decréscimo populacional e para a constituição de famílias com não indígenas e com indígenas de outras etnias, formando as "famílias caboclas" (Saraiva, 2007a, 2007b; Vieira et al., 2009).

No entanto os Yudjá, tanto os residentes na TI Paquiçamba quanto os do município de Altamira, guardam, em situações festivas e de guerra, uma identificação muito forte com o Xingu e sua paisagem percebida "em suas narrativas cosmo-históricas, na pintura corporal, nas canções Yudjá e no artesanato" (Saraiva, 2007a, p. 40).

A VGX, segundo Ab'Sáber (1996), faz parte da fall line zone (zona de linha de queda) sul amazônica, onde se situam alguns pontos favoráveis à implantação de hidrelétricas devido à existência de quedas naturais. Por isso, hoje, esses indígenas estão ameaçados pelo "Projeto de Barramento do Rio Xingu", através da implantação da UHE de Belo Monte, pelo consórcio de empresas estatais e privadas, principalmente do setor elétrico denominado Norte Energia S/A e, de acordo com o projeto, essa UHE terá capacidade total instalada de 11.233,1 MW e será a terceira maior do mundo e a segunda maior do Brasil, atrás apenas da binacional Itaipu (Saraiva, 2007a; Vieira et al., 2009).

Na configuração inicial do empreendimento, boa parcela da TI Paquiçamba seria inundada. Com o novo arranjo, houve redução da área do reservatório, eliminando a inundação dessa terra indígena. Ainda assim, a UHE de Belo Monte afetará de maneira significativa o cotidiano dessa comunidade. As principais interferências, diretas e indiretas são: reassentamento das comunidades indígenas (afetando o estilo de vida), inundação de áreas locais de valor espiritual, diminuição da caça, redução de áreas cultiváveis e aumento de doenças infecciosas (Sousa Jr.; Reid; Leitão, 2005; Vieira et al., 2009).

Do ponto de vista da pesca de peixes, por essa TI se constituir em fonte de consumo, comércio e lazer no médio rio Xingu (Saraiva, 2007a, 2007b; Ribeiro et al., 2008, 2009; Carvalho Jr. et al., 2009), a construção da UHE Belo Monte vai não só afetá-la, como também aos demais recursos naturais e sua biodiversidade.

O conhecimento empírico sobre os peixes está relacionado à compreensão do homem sobre os ecossistemas aquáticos e aos saberes dos sujeitos que neles interagem. Nesse sentido, alguns autores (Diegues, 1983; Castro, 1997; Loureiro, 1992; Posey, 2001) têm insistido que as propostas para o uso sustentável e a conservação da biodiversidade devem ser fundamentadas nas experiências dos antepassados e no fortalecimento das comunidades, com a valoração de seu saber local.

Buscando colaborar com a compreensão sobre quais saberes da experiência no cotidiano da pesca ajudam a qualificar as ações de conservação de 
peixes, especialmente os ornamentais, nesse estudo investigamos: Que saberes, dizeres e práticas sobre a pesca apresentam os índios yudjá, da TI Paquiçamba?

O presente estudo objetiva descrever conhecimentos dos índios yudjá, sobre peixes de importância comercial e/ou subsistência, de modo a ampliar tais conhecimentos, bem como servir de parâmetro para formulação de políticas de gestão e educação ambiental, voltadas para comunidades ribeirinhas.

\section{Os caminhos metodológicos}

Adotamos princípios da Etnoecologia como referencial metodológico, uma vez que é um campo de pesquisa científica transdisciplinar, a qual estuda os conhecimentos, crenças, sentimentos e comportamentos que intermedeiam as interações entre as populações humanas e os demais elementos dos ecossistemas, bem como os impactos ambientais, os quais podem daí decorrer. Esses estudos referem-se a conhecimentos que circulam as vivências dos povos tradicionais, ou seja, formas de uso e apropriação dos recursos naturais e da biodiversidade, por meio de sua inserção no meio natural, suas crenças, percepções, comportamentos, e também, das várias formas de classificar, nomear e identificar tais elementos em seus ambientes (Thé, 1999; Marques, 2001; Fernandes-Pinto e Marques, 2004).

Sabemos que as populações humanas têm habitado a Amazônia há pelo menos doze mil anos, desenvolvendo um amplo conjunto de práticas tradicionais e regras culturais relacionadas ao uso e manejo dos recursos naturais (Furtado, 1981, 1993, 2006; Loureiro, 1992; Santos; Santos, 2005). Nesse tempo, a região era explorada apenas pelos índios e os peixes já se constituíam em recursos naturais importantes para seu consumo, especialmente para aqueles que residiam nas margens dos rios (Meggers, 1977; Santos; Santos, 2005; Furtado, 2006), cuja pesca se dava de forma artesanal.

Essa modalidade de pesca é definida como aquela em que o pescador, sozinho ou em parcerias, participa diretamente da captura de pescado, usando para tal atividade instrumentos relativamente simples. As comunidades tradicionais pesqueiras fundamentaram suas atividades nesse vasto conhecimento empírico, adquirido e acumulado no decorrer de várias gerações. Nesse sentido, a intuição, a percepção e a vivência são partes desse saber tradicional que consolida a prática da pesca, especialmente na Amazônia paraense. Assim, o registro desses saberes quase sempre é mental e se transmite pela tradição oral de pai para filho, de geração a geração. Nesse particular, as faixas etárias mais velhas exercem um papel relevante na socialização desses saberes (Furtado, 1993; Carvalho Jr. et al., 2009).

Consideramos que as falas e os fazeres, quando se trata de Etnobiologia, são de fundamental importância para a pesquisa, porque por meio deles, se 
constroem a história e se dá sentido a ela, uma vez que: "a memória assume importância crucial nesse processo de reconstrução da identidade" (Saraiva, 2007a, p. 35).

Com essa compreensão, trabalhamos na TI Paquiçamba, com autorização da Fundação Nacional do Índio (FUNAI), de 2008 até o presente momento.

Para conhecer o cotidiano dos pescadores yudjá, visitamos as 18 casas da aldeia, totalizando pouco mais de 80 índios. Entrevistamos 26 moradores, indicados pelos próprios membros da comunidade e, destes, para participar do estudo, selecionamos 18 entre os que pescam atualmente e os aposentados. As entrevistas foram filmadas, gravadas e transcritas.

Procuramos, ainda, acompanhar os pescadores yudjá em sua lida diária, nas áreas de coletas, tanto aquelas localizadas próximas como as mais distantes da VGX, a fim de observar locais de pesca, identificar os principais peixes de ocorrência, fazendo o registro fotográfico e anotações em caderno de campo das atividades, para construir o estado de arte da pesca no Xingu.

Os dados coletados, nas diferentes etapas da pesquisa, embasaram a construção dos mapas cognitivos ${ }^{1}$, baseado em Jardim (s.d.), em que foram pontuadas as áreas de pesca, com seus principais ambientes (ilhas, pedrais, cachoeiras, corredeiras, grotas, sequeiros, praias, canais, furos, entre outros locais). É interessante ressaltar que o mapa foi desenhado pelos Yudjá na perspectiva da margem, portanto, ao contrário da imagem vista por satélite, que utilizamos em campo.

Para complementação das informações desenhadas no mapa, usamos a técnica da realização de "turnês" pela área de estudo, na qual um ou mais consultores culturais são utilizados como guias (McCurdy, Spradley e Shandy, 2004), e, dessa forma, conseguimos identificar e georreferenciar os pontos traçados no mapa.

Realizamos, também, identificação dos peixes por indígenas não participantes das pescarias. Para tanto, foi construído um painel fotográfico com os peixes de ocorrência na área da VGX. Esse painel era apresentado aos participantes do estudo, que deveriam responder: Qual o nome desse peixe? Como você reconhece esse peixe? Onde esse peixe é encontrado? Para que ele serve?

Tomamos como base, para interpretarmos os dados obtidos, a análise de conteúdo, entendida como um conjunto de técnicas destinadas "à descoberta do que está por trás dos conteúdos manifestos, indo além das aparências do que está sendo comunicado" (Minayo, 2002, p. 74).

\footnotetext{
${ }^{1}$ Mapa cognitivo ou imaginário: um termo que utilizamos, no presente estudo, para o mapa desenhado pelo pescadores yudjá, de forma livre (sem georreferenciamento) e incluindo os acidentes geográficos. Também chamamos como "mapas de uso" ou "mapa falado".
} 
Neste estudo, apresentamos as falas dos entrevistados em linguagem coloquial, para melhor compreensão do leitor sobre os assuntos tratados com os indígenas. Além disso, por questões éticas, não identificamos as falas dos 18 pescadores e da comunidade, uma vez que, nas conversas informais e mesmo nas entrevistas, normalmente, estavam mais de uma pessoa no local, assim, uma pessoa completava o raciocínio do outra, sendo, portanto, consideradas "falas consensuais".

\section{O rio Xingu: pescadores yudjá e peixes}

A região do Xingu possui um período demarcado por chuvas torrenciais (inverno-cheia) entre os meses de dezembro a abril, e um curto período seco ou de diminuição de chuvas (verão-seca), entre os meses de julho a outubro; essa variação sazonal da precipitação está de acordo com a do estado do Pará, segundo Moraes et al. (2005). Em alguns trechos no período de seca somente é possível navegar com rabeta ${ }^{2}$ ou canoa, e, dependendo da magnitude da estiagem, em alguns trajetos é impossível de se trafegar (Carvalho Jr. et al., 2009; Vieira et al., 2009).

Nos caminhos e trajetos utilizados pela comunidade indígena, há diversos furos, canais, cachoeiras, lagos, sequeiros e poções, sobre eles, alguns comentários de índios yudjá.

Os canais são navegáveis durante o ano todo, pois não secam como os furos:

Quando a gente pega os canais de inverno, fura o caminho e aí fica mais perto de viajar. No verão a gente pode andar a pé, porque em alguns lugares até seca.

As cachoeiras por sua vez:

No verão, a cachoeira Curupira fica com a água muito baixa, aí a gente só viaja com casquinho (canoa) ou rabeta e com pescador experiente, que conhece cada parte... e no inverno, na cachoeira Jurucuá não dá de rabeta, porque a água é grande. Na cachoeira do Jurucuá no verão fica um enorme 'sequeiro', porque a água baixa e aí aparecem os pedrais.

No rio Xingu, em locais de maior profundidade com ou pouca correnteza e sem cachoeiras, encontram-se também os poções. Em alguns desses locais:

Chegam a mais de trinta metros, quando chove, e, aí, é muito perigoso durante a cheia.

A gente pode pescar peixes grande, mas tem pescador que nem vai, porque aí vive a Cobra Grande.

\footnotetext{
${ }^{2}$ Rabeta: canoa que utiliza motor de popa movido a gasolina ou gás butano (botijão de cozinha). 
Observamos que a comunidade yudjá possui saberes diversos sobre como as águas do Xingu se comportam nas duas estações do ano e também de como sobreviver na região. Outro aspecto que chama a atenção é a incorporação de valores míticos, que orientam suas práticas, indicando, de certa forma, que seu imaginário incorpora saberes de seus ancestrais.

Quanto às atividades específicas dos pescadores, é consenso que a pesca artesanal de peixes, em geral, já se constituía num dos recursos naturais importantes para a manutenção das populações indígenas, nos primórdios da civilização humana na Amazônia (Meggers, 1977; Santos; Santos, 2005).

\section{Ocorrência e distribuição dos peixes na percepção dos Yudjá}

Como o conhecimento e a percepção dos diferentes espaços em que os peixes podem ocorrer são de grande importância para a atividade pesqueira, os pescadores Yudjá categorizaram os ambientes aquáticos do seu entorno em quatro grandes divisões hidrográficas, denominadas "rio", "igarapés", "gapós" (igapós) e "lagos", e suas subcategorizações/subdivisões, descritas e nomeadas pelos pescadores destacando-se: "canais", "ilhas", "corredeiras", "sequeiros", "poções", "remansos", "baixões" (planície), "barrancos", "furos", "grotas", "tocas" (burracos no fundo do rio, sendo citadas espécies que fazem buraco e as que usam buracos já feitos), "mocororo" (pequenos buracos nas pedras), "galhada de pau" (troncos e folhiços), "sarobal" (vegetação sazonalmente inundada, no período de grandes chuvas e enchentes), "lajes", "fendas", "lama", "areia", "gorgulho" (pedregulhos do tipo cascalho/seixo), "beira" (margens) e "praias", que correspondem aos ambientes fluviais do rio Xingu, encontrados nas áreas do entorno da TI Paquiçamba. Embora os pescadores tenham reconhecido a ocorrência de diferenciados peixes em cada tipo de ambiente, a maioria citou a relação de peixes associados aos "pedrais": com "remanso", com "corredeiras", com "gorgulhos" e com "lajes", provavelmente, porque esses peixes fazem parte de um conjunto diferenciado, de alto valor comercial, denominado 'família dos carizinhos' (família Loricariidae).

Os Yudjá reconheceram os peixes com ocorrência restrita apenas em um desses grandes ambientes:

O filhote (Brachyplatystoma filamentosum) só dá no canal do rio e o zebrinha (Hypancistrus zebra) só dá nos pedrais, no rio.

E os que ocorrem em mais de um ambiente, mas com abundância diferenciada:

Os amarelinhos (Baryancistrus xanthellus) dá mais nos pedrais e no lago também dá, mas é menos quantidade.

E os que estão distribuídos de forma mais ou menos homogênea: 
Os pacus (Myloplus e Myleus spp.) dá em qualquer lugar.

Embora sejam consideradas duas estações bem definidas: inverno-cheia e verão-seca, para o estado do Pará (Moraes et al., 2005; Carvalho Jr. et al., 2009; Vieira et al., 2009), os pescadores yudjá reconheceram quatro épocas do ano: "cheia", "vazante", "seca" e "enchente", as quais correspondem às estações do calendário dos pescadores do Xingu e são baseadas na percepção do ciclo sazonal de distribuição temporal dos peixes, como exemplifica um pescador:

Tem a 'água clarinha' (sem água da chuva) e a 'caldada' ou 'truvada' (com água da chuva).

Assim, os Yudjá categorizaram os peixes que "dão o ano inteiro" e os peixes que "não dão o ano inteiro"; dos que têm safra:

O pocomom (Tocantinsia piresi) que dá de mais na água 'truvada', no meio das 'gaiadas' no 'gapó'.

Na distribuição espacial dos peixes também está envolvida a percepção de movimentação ou migração entre hábitats e a ocupação de hábitats diferenciados ao longo do ciclo de vida (período reprodutivo) e do ciclo ontogenético (diferenças de hábitat entre juvenis e adultos):

A gente pega muita picota ouro (Scobinancistrus aureatus) e tamanco (Panaque cf. armbrusteri) nas fases inicias e ou juvenil, nas águas 'caldadas' no sarobal.

O cari marrom (Hypancistrus sp.) só dá no fundo, lá no poção (normalmente no estágio adulto), onde cria ou cresce. O zebra (Hypancistrus $z e b r a)$ fica com uns ovinhos no mocororo.

O pacu (Myleus spp), a curimatá (Prochilodus nigricans), o piau (Leporinus spp) e a ariduia (Semaprochilodus brama) é mais na enchente: chega na veia d'água onde tem uma sangra fica aquelas carreiras delas. Ali desova pra trás. Ali perde mais do que escapa (na enchente, o aumento do volume de água carreia milhares de ovos e larvas de peixes com mais facilidade; essa forma de reprodução externa inclui grandes perdas, pois fica à mercê do ambiente).

Os Yudjá reconheceram ainda a ocupação de alguns ambientes relacionada ao hábito alimentar dos peixes, categorizando os que comem "lama/ lodo", "areia", "folha, fruto, semente" e "insetos", dentre outros. No entanto a associação de um peixe a um hábitat preferencial não significa que a sua ocorrência seja exclusiva desse ambiente, como é o caso do amarelinho ( $B a-$ ryancistrus xanthellus) que se encontra mais facilmente nos pedrais. 


\section{Saberes sobre métodos e apetrechos de pesca dos Yudjá}

Baseado no conhecimento do comportamento alimentar dos peixes, os pescadores utilizam iscas vivas, tais como: “caranguejo" (crustáceo), 'gongo' (larvas de besouro coleóptera), várias espécies de peixes inclusive de gêneros diferentes como as piabas (Moenkhausia spp., Astyanax spp., Bryconops spp.), mandizinho (Pimelodella sp.), 'milonga' (minhoca - Oligoqueta), 'buzo' (molusco Gastropoda):

Os tucunaré pintado e amarelo (Cichla spp) a gente pega usando piabas (Moenkhausia, Astyanax e Bryconops spp.), perto dos remansos, nos pedrais.

Os pacus (Myloplus e Myleus spp) e o matrinchã (Brycon sp) a gente pesca com iscas de frutos e sementes (seringa, bananinha, goiaba de junho, juari, socoró, goiabinha, sarão, landi, uxirana, golosa, muruci ...).

As 'raia' (arraias) preta (Potamotrygon leopoldi) grande pega com piaba (Moenkhausia, Astyanax e Bryconops spp.). Prá manter raia no viveiro coloco buzo e pedaços de peixes.

Outros saberes são evidenciados pelos vários métodos e ou pelos apetrechos de pesca, como a linha de mão e anzóis, os mais utilizados para capturar as iscas vivas. Já para capturar os peixes, para consumo e comércio, assim se referem:

O curimatã (Prochilodus nigricans), ariduia (Semaprhochilodus brama) e as branquinhas (Curimata e Cyphocharax spp.) a gente pega atirando várias vezes a tarrafa ${ }^{3}$. A tarrafa a gente joga na água que abre circular, em locais rasos e com pouco mato.

A tarrafa de tela é boa para ser usada no período da seca, de noite, nos remansos dos pedrais e na praia, porque lá é calmo. A tarrafa de linha fica pesada, porque é feita de algodão e se encharca, aí não escorrega, é melhor ser usada nos pedrais e nas corredeiras.

Os pacu e o matrinchã a gente pesca com malhadeiras ${ }^{4}$. A gente pode usar a malhadeira onde não tem muita correnteza, presa na superfície ou no fundo, e a gente fica esperando... também pode fazer o 'bate' (bloqueio) nas margens dos pedrais e das praias e vai 'lavrando' a área.

A piranha preta (Serrasalmus rhombeus) e camari (Serrasalmus sp.) são os principais 'predradores' dos peixes quando malhados.

\footnotetext{
${ }^{3}$ Tarrafa: rede miúda de mão (com malha pequena: $<50 \mathrm{~mm}$ ) e apresentam suas bordas com chumbos.

${ }^{4}$ Malhadeira: rede retangular construídas com nylon multifilamentos, sendo a sua altura definida conforme o número de filas, que os Yudjá chamam de palmos.
} 
O tucunaré nos pedrais, a gente pega também com pindá 5 . A gente pode pescar só com o pindá ou fazer anzóis de gaio (galho).

A gente usa o ferro ${ }^{6}$ quando mergulha nos pedrais e nas corredeira: a gente vê o cari, o piau (várias espécies, inclusive de gêneros diferentes) e, aí, arma utilizando a liga em volta do braço, atirando no peixe.

No lago, a gente pega caratinga (Geophagus cf. altifrons) e pacu com linha e anzol e quando bem limpinha a água dá pra usar a flecha ${ }^{7}$.

Com o cacuri ${ }^{8}$ a gente pega, mandii (Pimelodella e Pimelodus spp.), traíra (Hoplias gr. malabaricus), aracu (Leporinus fasciatus), pacu (Myleus spp) e jeju (Hoplerythrinus unitaeniatus).

O pano a gente enrola nas mãos, para proteger do ferrão da raia... quando a gente 'tanger' (provoca), a raia se enterra e precisa ser pega segurando pelo rabo.

O puçá ${ }^{9}$ serve para pescar picota ouro (Scobinancistrus aureatus), assa (Pseudacanthicus sp) .... na seca, de dia e de noite, mais nas margens das ilhas e pequenas corredeiras com 'gorgulho' e no inverno, entre as 'ramas' das plantas 'afundada' (submersa), no meio do sarobal.

Os pescadores yudjá lembraram também do timbó, mas que atualmente não estão usando mais, porque esse tipo de modalidade é proibido pelos órgãos fiscalizadores, em vista de matar indiscriminadamente várias espécies de organismos aquáticos:

Tem o preto e o branco, mas o veneno do preto mata mais. O timbó fica 'embolotado' (entrelaçado) com outras plantas... A gente pode cortar com terçado, no toco, ou pode arrancar com as raízes, que são compridas ... depois o timbó é amarrado em feixe. O timbó precisa primeiro ser bem batido com pedaços de pau, bater bem mesmo, para o cipó ficar bem amassado. Depois cava o barro e mistura com o timbó. Vai pisando o barro dentro da água e o timbó se espalha na água. O timbó é melhor usar no remanso do rio Xingu e no verão, quando a água está baixa.

\footnotetext{
${ }^{5}$ Pindá: linha de algodão, com um pano vermelho e três anzóis amarrados na ponta.

${ }^{6}$ Ferro: espécie de arpão com haste de ferro com a ponta afiada e na outra extremidade tem uma liga de borracha hospitalar.

${ }^{7}$ Flecha: a haste é feita de flecha, taboca ou canabrava (madeiras leves que flutuam na água) com ponta de metal, osso e madeira e o arco é feito de ipê, paxiuba e patí.

${ }^{8}$ Cacuri: armadilha confecciona com talas de palmeira (Marajá) amarradas com fio de envira (casca da Embaúba), cipó titica ou cordão de algodão.

${ }^{9}$ Puçá: rede cuja haste circular é feita de ferro ou cipó e o saco, em forma de funil, com sobras de malhadeira.
} 
Entre as artes de pesca também é praticado o mergulho. No mergulho livre, a coleta dos peixes é feita manualmente com uso de mascareta (máscara de mergulho de borracha de silicone ou não e visor com vidro temperado ou não). O procedimento, segundo os pescadores yudjá é o seguinte:

Com a vaqueta ${ }^{10}$ a gente vai tocando devagarinho o carizinho que está escondido nas brechas das pedras, lajes ou nas gaiadas. Quando ele sai a gente prende a cabeça (porção pré-dorsal) ou a nadadeira (o primeiro raio da nadadeira peitoral ou dorsal, que é duro, bastante ossificado) com a ponta da vaqueta ou coloca a tarrafinha ${ }^{11} \mathrm{em}$ cima, puxa devagar cada cari da redinha, aí consegue pegar o peixe com cuidado com as mãos e coloca o peixe no 'vridro' (recipiente plástico).

A gente pode colocar pedras pequenas e lisas, formando montes nas lajes, os peixes se escondem aí, então, a gente coloca a tarrafinha e pega os peixes. Na cheia, a gente usa o puçá que ajuda a 'pegá' os peixe nos paus e gaiadas do sarobal.

Como os acaris (loricarídeos) apresentam placas com numerosas fileiras de odontodes espinhosos e como os pescadores yudjá não utilizam nenhum equipamento e ou artefato de proteção, apresentam no corpo (mãos, braços, cabeça e pés) as marcas dos cortes frequentes causados por esses espinhos, por pedras pontiagudas e soltas no fundo e por ferradas de arraia.

Já no mergulho de compressor, comum na pesca ornamental, é utilizado um compressor de encher pneu adaptado a um motor de gasolina, no qual é acoplado um fio elétrico entrelaçado a uma mangueira transparente e, em sua extremidade, a "chupeta" (bocal por onde o pescador recebe o ar) e a lanterna (comum, mas com lâmpada de motocicleta). Consideramos "esse arranjo" em condições impróprias para a saúde, uma vez que:

Às vezes, o ar que a gente chupa 'é ar de motor' (como não existe qualquer tipo de filtro, os pescadores acabam respirando o ar com cheiro de gasolina). A lanterna serve para gente ver os cari no fundo (que pode chegar a $20 \mathrm{~m}$ de profundidade).

Já aconteceu do motor explodir... da mangueira arrebentar ou prender nos pedrais. Na corredeira já aconteceu de afundar o casco com motor e perder a produção do dia, o casco e motor a gente mergulha nos pedrais e apanha, mas a produção tem que começar tudo de novo e mais despesa.

A gente pesca assim de manhã e de noite ... fica lá embaixo duas, três horas direto, todo mundo fica 'ingilhado' (engelhado). Dói tudo.

\footnotetext{
${ }^{10}$ Vaqueta: também chamado pelos não-índigenas de espada, é um pedaço de madeira resistente com dimensões de 40 a $70 \mathrm{~cm}$ de comprimento e, 2 a $4 \mathrm{~cm}$ de largura. Possui sua extremidade com uma ponta fina e bem lixada.

${ }^{11}$ Tarrafinha: rede para pesca de peixes ornamentais, na fase juvenil, feita de algodão.
}

Tellus, ano 11, n. 21, jul./dez. 2011 
Assim, no período mais chuvoso, os pescadores relataram sentirem dores corporais, após muitas horas de submersão e também reclamaram a exposição a baixas temperaturas, pressão e maior turbidez da água, forte correnteza e condições precárias na coleta. Já sobre o período menos chuvoso, salientam que precisam despender mais tempo para os deslocamentos. Também narraram casos de pescadores, que morreram ou ficaram com sequelas (perda ou deficiência auditiva, alterações visuais, reumatismo...), após anos nessa atividade.

As pescarias de subsistência e comercial são realizadas normalmente por dois ou três pescadores, tanto defronte à TI Paquiçamba como no entorno. Ao realizar as pescarias em locais mais distantes, principalmente nas áreas das cachoeiras do Jericuá e do Paquiçamba, e no rio Bacajá, chegam a permanecer acampados nas margens de ilhas, praias e barrancos por um período que vai de cinco a oito dias. Utilizam canoas a remo, transportadas por barcos do contratante (os patrões de pesca), ou rabetas, de propriedade das famílias nucleares. Nesse sistema de parceria, negociam com atacadistas (patrões) o preço, material de pesca e o rancho (alimentação) a ser utilizado nos dias de serviço. Já nos arredores da TI Paquiçamba, pescam sozinhos ou em parceria, com os familiares, que participam diretamente das capturas.

Como as capturas de peixes ornamentais são realizadas durante aproximadamente uma semana e a comercialização é feita geralmente uma vez por semana, os peixes devem permanecer armazenados em viveiros, nos períodos entre a captura e a comercialização. Os viveiros são construídos em madeira (piqui ou ipê), revestidos de tela plástica com fundo de madeira, sendo que o tamanho do viveiro varia de acordo com os tamanhos dos peixes. Como os viveiros devem permanecer na água do rio, alguns pescadores os revestem com tela de arame para evitar predadores como traíras e piranhas, também utilizam tampas para proteger de caranguejos. Algumas vezes usam até mesmo cadeados para evitar a fuga dos peixes, quando os viveiros estão submersos nas corredeiras ou roubos, enquanto estão mergulhando ou caçando.

\section{Os peixes ornamentais nas vivências dos Yudjá}

No entanto, pelas falas dos Yudjá, constatamos que os conhecimentos sobre peixes ornamentais são relativamente recentes:

A gente começou a trabalhar nisso faz uns 20 anos. A borracha não dava mais para nada, foi uma oportunidade de a gente começar nova vida. Os estrangeiro gostou dos peixes e pagava bem. 
Assim, consideramos que os conhecimentos tradicionais sobre peixes ornamentais se baseiam mais no acúmulo de conhecimentos empíricos vivenciados no dia a dia da pesca, impulsionado pelo ciclo produtivo desses organismos, do que pelo número de anos nessa atividade.

Carvalho Jr. et al. (2009), estudando os pescadores ornamentais do médio rio Xingu, não indígenas e não moradores da TI Paquiçamba, constataram que a maioria (61\%) nasceu no Pará, e o restante veio de outros estados, atraído pelo ciclo da borracha. Portanto a maioria dos moradores da região do rio Xingu (Yudjá ou não-índios) lida com a pesca ornamental e adquiriu seus conhecimentos através de observação na natureza ou de informações por outras pessoas.

Observando a natureza, os Yudjá reconheceram os fatores ambientais que determinam a disponibilidade - oferta ou escassez - da pesca na TI Paquiçamba. Por exemplo:

No tempo seco, pegamos todo tipo de peixe, porque o rio fica mais baixo e os peixes ficam mais 'juntinho' e 'fácil' de ver. No período das chuvas, a gente pesca mais os peixes que gosta de se juntar (formar cardumes) ou os peixes que moram em 'gapós'. O 'gapós' serve de abrigo e alimentação para os peixes e também para tracajá e jacaré. No 'gapós' têm muita folhas, frutos, flores, raízes, insetos para peixes.

No tempo frio, o rio fica mais fundo, mais forte e a água fica mais fria, 'caldada' e 'truvada' a gente trabalha mais, porque é difícil ver os peixes.

Algumas espécies de peixes, principalmente as de interesse comercial, apresentam um padrão sazonal de ocorrência bem conhecido pelos pescadores indígenas. Entre os acaris, por exemplo:

O carizinhos prá venda tem: amarelinho (Baryancistrus xanthellus), bola azul (Oligancistrus sp. e Parancistrus sp.), onça (Leporacanthicus heterodon), aba laranja (Baryancistrus chrysolomus), marrom (Hypancistrus sp.) mais no tempo seco. Os cari assa (Pseudacanthicus sp.), picota ouro (Scobinancistrus aureatus) e boi de bota (Panaque cf. armbrusteri) têm mais na cheia. Cabeça chata (Hopliancistrus tricornis) e ancistro (Ancistrus sp.) têm muito o ano todo.

Já os pacus:

Aparece toda qualidade (Myloplus, Ossubtus e Myleus spp.) quando a água do rio começa a subir.

Como os Yudjá, além da pesca ornamental, também pescam para sua subsistência e comercialização com alimentos, têm uma percepção geral do comportamento dos peixes, ou seja, a maioria dos pescadores afirmou que o período da manhã é melhor para se capturar os peixes ornamentais e, no período da noite, o comestível, salientando:

Amarelinho a gente pega de dia, quando o dia já tá esquentando. 
Tucunaré (Cichla spp.) e pescada branca (Plagioscion squamosissimus) (peixes utilizados mais para alimentação) a gente pega no final da tarde. De tardinha prá noite a gente pega com malhadeira os pacu (Myleus e Myloplus), fidalgo (Ageneiosus inermis) e cachorra (Hydrolycus armatus).

Os peixe liso (pirarara - Phractocephalus hemioliopterus, surubim - Pseudoplatystoma fasciatum, barba chata - Pinirampus pirinampu, braço de moça - Hemisorubim platyrhynchos e outros bagres) a gente pesca de noite prá amanhecer.

A região do médio rio Xingu é caracterizada pela presença de baixões e pedrais (Saraiva, 2007a; Carvalho Jr. et al., 2009; Vieira et al., 2009), que, segundo os Yudjá, são: "Local onde está os melhor peixes, mas ali fica alagado nas cheias. Aí é mais fácil pegar os cari nos pedrais no período seco".

Os pescadores também citaram diferentes artes de pesca. Somo exemplo disso, a modalidade de pescar o "cari" de acordo com a finalidade de uso:

Os adulto a gente pega prá comer, usando 'mascareta' e também usando ferro ou tarrafa. Com 'tarrafinha' ou 'vaqueta' a gente pega os "carizinhos" (fase juvenil), que a gente guarda no 'vrido' e depois fica vivo nos viveiros, até vender.

Os Yudjá têm a percepção de que a pesca depende do pescador, do local e da época para deixar na basqueta (recipiente plástico de 40 litros):

É assim: se o pescador é brabo e pesca tudo e não tem classificação (pesca indiscriminadamente e mantém os peixes juntos, independente dos tamanhos) o carizinho fica doente e morre tudo. Se o local tá muito batido (muito explorado em termos de pesca, fluxo de transporte, exploração de garimpo), não serve: o carizinho fica com vermelhão (fungo na pele do peixe).

Se é seca, os carizinhos estão magros e por isso a gente classifica mais (mais seletivos na coleta, intensificando sobre as espécies de maior valor no mercado), pega mais zebra ou acari marrom. Na cheia é mais difícil, a gente pega o que dá.

Portanto, no verão, devido à maior disponibilidade de hábitats, os Yudjá usam tecnologias de pesca mais diversificada, aumentando a captura de peixes. No inverno, ao contrário, a menor disponibilidade de áreas de pesca e a dispersão dos peixes diminuem a oferta, forçando-os a procurar outras fontes de subsistência e/ ou de comércio. No auge da cheia, alguns pescadores substituem suas atividades de pesca pela agricultura e extrativismo.

Quando a água sobe muito a gente prefere caçar paca, veado, porco ... Também pega fruto para comer: açaí, bacaba, cupuaçu, cacau do mato, castanha do Pará ... 
A gente tira a borracha da seringueira.

Toda família ajuda, a gente planta junto milho, arroz, mandioca, cacau, mamão, banana, cará, abóbora ...

\section{Mapas cognitivos: os saberes da vivência}

Com as entrevistas, os depoimentos, as observações in loco e os registros de aspectos espaciais e temporais sobre as formas de uso e de ocupação dos peixes, na TI Paquiçamba, foi possível a elaboração de mapa cognitivo, com auxílio dos pescadores (Figura 1).

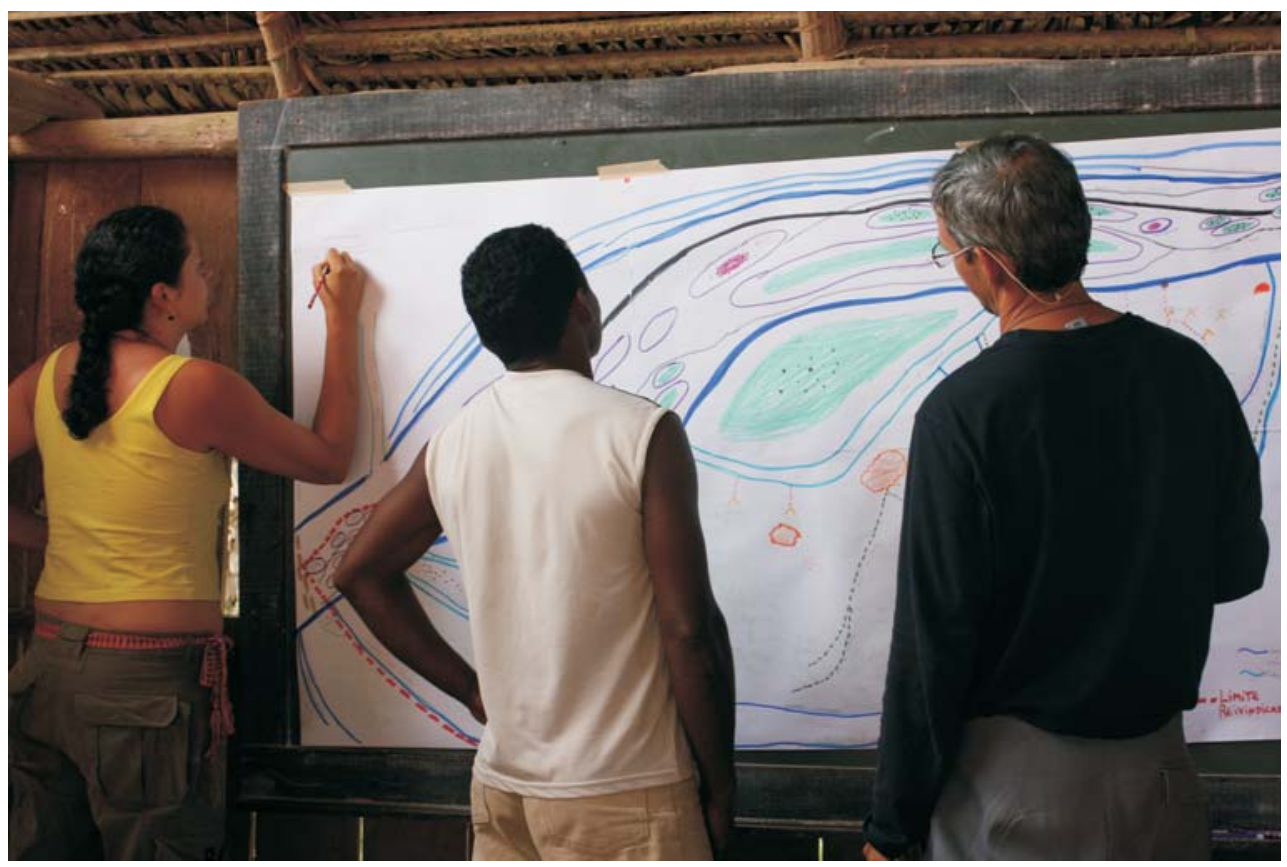

Figura 1 - Elaboração do mapa cognitivo da TI Paquiçamba, pelos índios yudjá.

Para tanto, confeccionamos um painel fotográfico com os peixes de ocorrência na área da VGX, o apresentamos aos participantes do estudo. Aos serem perguntados sobre o nome do peixe e as características de reconhecimento, obtivemos as seguintes respostas:

O cari cabeça chata (Hopliancistrus tricornis) tem bolinhas amarelas, e o cari alicate (Pseudancistrus barbatus) tem os espinhos nas guelra. 
Os 'peixes branco' têm escamas. São as piabas, curimatá, cachorras (Hydrolycus spp.), pacus e piranhas (Serrasalmus spp.).

Tem o peixe elétrico (Electrophorus electricus), o sarapó (Gymnotus spp.), o itui (Eigenmannia, Rhamphichthys, Sternopygus spp.) que tudo é parente.

Até o momento, registramos 160 espécies de peixes, distribuídas em diferentes ambientes aquáticos existentes nas áreas de uso dos pescadores yudjá na TI Paquiçamba. Verificamos que a identificação/caracterização feita pelos pescadores (nome regional) estava de acordo com a classificação científica (Eschmeyer, 1998; Reis; Kullander; Ferraris, 2003; Buckup; Menezes Filho; Ghazzi, 2007, dentre outros).

Como a pesca ornamental tem um mercado próprio, que atende principalmente os atacadistas do município de Altamira, o impulso da subsistência forçou os Yudjá a procurar novas perspectivas:

A gente está em busca de novas variedades de peixe.

Nesses vinte anos morreu muito peixes, hoje já diminuiu bastante. A gente aprendeu vendo peixe morrendo na nossa mão.

A gente não recebe nada do pessoal dos aquário de Altamira; tudo é descontado nos cari.

Cabe ressaltar que o tamanho dos peixes ornamentais capturados depende da espécie, mas varia de 2,5 a $25 \mathrm{~cm}$, e o tamanho médio preferido pelo mercado é de $8 \mathrm{~cm}$ de comprimento total. Como algumas espécies de uso alimentar indígena e ornamental estão sendo comercializados ainda nos estágios juvenis, constatamos um perigo adicional para a preservação dos estoques pesqueiros.

Outra informação preocupante é que, nos arredores da TI Paquiçamba, são encontradas várias espécies de peixes ornamentais consideradas endêmicas, dentre elas o acari zebra, o qual, de acordo com os pescadores yudjá, é restrito à localidade do Gorgulho da Rita (Altamira) até a região de Belo Monte; portanto encontra-se sob ameaça, com o barramento. Outra espécie considerada endêmica, como o pacu capivara, já é considerada espécie ameaçada, de acordo com as instruções normativas do IBAMA, publicadas em $2008^{12}$.

Já a pesca da arraia preta endêmica do rio Xingu foi proibida desde 2005, mas voltou a ser permitida através de cotas (IBAMA, 204-2008) ${ }^{13}$. Além dessa

\footnotetext{
${ }^{12}$ Ver <http:/ / www.ibama.gov.br/documentos-recursos-pesqueiros/instrucao-normativa> . ${ }^{13}$ Instrução Normativa IBAMA 204, de 22 de outubro de 2008: estabelece normas, critérios e padrões para a exploração com finalidade ornamental e de aquariofilia de exemplares vivos de raias nativas de água continental, Família Potamotrygonidae.
} 
permissão, outras 254 espécies de peixes foram liberadas para comercialização e exportação (IBAMA, 203-2008) ${ }^{14}$.

Como o "zebrinha" destaca-se entre os principais representantes da ictiofauna de interesse ornamental existente no rio Xingu, devido ao seu porte pequeno e valor comercial alto, alguns países já o produzem em ambientes artificiais. Atualmente, existe grande interesse por parte de instituições governamentais e do setor produtivo em realizar programas de manejo sustentável do acari zebra.

No entanto, com o patrimônio adquirido e testado ao longo de 20 anos de pesca ornamental, partindo da observação que os acaris são herbívoros, os Yudjá já tentam o seu cultivo de forma rudimentar, como demonstra esse depoimento:

Primeiro a gente colocou os peixe na basqueta e viu quantos ficou vivo ali. Hoje a gente coloca vinte caris por basqueta, aí vai olhando todo dia e vê se os cari está morrendo ou se está rasgado (peixes danificados, principalmente as nadadeiras).

Continuando o mesmo raciocínio outro pescador yudjá disse:

Aí a gente fez assim: colocou três basqueta montoada e com furo na correnteza, deixando a água passar na basqueta. Aí a gente viu que os carizinho não morria nem ficava doente, com vermelhão.

Se a gente montá viveiro acho que leva 200 cari.

Em geral, algum alimento é colocado nos viveiros para assegurar a sobrevivência dos exemplares. Assim, procuram reproduzir o hábitat dos acaris:

A gente põe pedras lisas (pedras planas) e deixa montoadas dentro da basqueta, para criar limo e os caris se acostumar. Aí os carizinho acaba ficando escondido qui nem no rio. Eles se alimentam do lodo (limo). Aí a gente foi testando qual o número, tamanho e tipo de pedras que os carizinho gostavam mais.

Os conhecimentos dos Yudjá sobre a reprodução dos acaris auxiliam o cultivo:

Os caris põe ovinhos um pouco cada vez (desovas parceladas) que podem ocorrer durante a seca ou durante o ano todo.

A construção do UHE de Belo Monte é uma realidade para a região da VGX e provocará a diminuição da vazão nessa área, principalmente na margem esquerda, que apresenta áreas isoladas no período natural de seca, como na localidade do Furo Seco. Um dos impactos ambientais para a região

\footnotetext{
${ }^{14}$ Instrução Normativa IBAMA 203, de 22 de outubro de 2008: dispõe sobre normas, critérios e padrões para a explotação com finalidade ornamental e de aquariofilia de peixes nativos ou exóticos de águas continentais.
}

Tellus, ano 11, n. 21, jul./dez. 2011 
da VGX e discutidos entre os indígenas tanto Yudjá como Arara é a redução da vazão do rio Xingu, causando diversos impactos para a biodiversidade, principalmente nos organismos aquáticos, reduzindo os recursos pesqueiros. Assim, os próprios índios já manifestaram interesse em aprender como cultivar os peixes para comercialização e subsistência.

Quanto à percepção sobre alguns problemas ambientais, pescadores yudjá que já trabalharam no garimpo de ouro na VGX refletem:

De 2003 a 2004, trabalhei no garimpo da Ilha Bela, que deixou muito estrago, a gente agora está tendo diminuição de bicho e peixe para comer.

Ainda bem que o garimpo durou apenas dois anos, porque além dos problemas nos rios, ainda veio muita gente de fora para cá... não tinha lugar para todo mundo ficar.

Relacionam também esse fato com os possíveis problemas que serão gerados com a construção da UHE de Belo Monte:

Virá muito gente de fora para a construção e vai dar muita violência.

Vai acabar com os pedrais, que é a casa do acari zebra.

A derrubada de muitas árvores, no final, vai deixar os rio mais raso.

Se a água não subir nas ilhas, o abio e o jauari vai cair no seco e vai diminuir o alimento para o matrichã, pacu...

Se no inverno a água não sobe nas ilhas e baixões, alguns peixes não têm onde desovar e crescer (ficam sem berçário).

A gente precisa dos rios e da mata para nossa vida.

Por essas falas, embora não se tenha perguntado diretamente "como vêem e consideram o ambiente em que vivem" percebemos que os Yudjá apresentam a noção de que é necessário "preservar o local para assegurar o futuro"; uma visão naturalista embasada em fatores abióticos e bióticos de causa e efeito, posicionamento já evidenciado por outros autores, com outros públicos-alvo, não indígena (Sauvé, 1994, s.d.; Reigota, 2004; Santana, 2004; Berna, 2005; Dantas; Nakayama; Santana, 2009; Santos; Santana; Nakayama, 2010; Silva et al., 2010).

Portanto os Yudjá naturalmente foram construindo um protocolo de boas práticas (para coleta, para armazenagem e para classificação etnoecológica) ao longo dos anos. Assim, consideramos que estão aptos para participarem de oficinas de manutenção em cativeiro e contribuir com suas experiências em áreas naturais, a fim de viabilizar a manutenção e a produção de algumas espécies principalmente as ornamentais, porque exigem menor área para 
cultivo em cativeiro (seja em áreas terrestres ou em naturais monitoradas) com maior valor agregado.

Em vista do exposto, consideramos que, em sua luta por melhores condições de vida, os pescadores yudjá desenvolveram tecnologias adaptadas às suas necessidades e especificidades; portanto merecem apoio da FUNAI no sentido de coordenar ações e investimentos com outras instituições como o Ministério do Meio Ambiente (MMA - Carteira Indígena), Ministério do Desenvolvimento Agrário (MDA), Ministério da Pesca e Aquicultura (MPA), Governo Estadual, Prefeituras, Secretarias Estaduais, Organizações não-governamentais indígenas e de Assistência Técnica e Extensão Rural, entre outras, para estimular o desenvolvimento da piscicultura familiar indígena. Por mais que seja hoje complexo o funcionamento da piscicultura na TI Paquiçamba, essa atividade de subsistência poderá significar sólidos aprendizados para o futuro da criação de peixes no local.

A Figura 2 é o "calendário sazonal etnoecológico", uma tentativa de interpretação dos relatos dos pescadores yudjá e suas percepções e atividades produtivas na TI Paquiçamba e entorno, a fim de facilitar o entendimento das dimensões espaço/tempo das formas de ocupação dos peixes e, principalmente, o uso dos recursos naturais. 


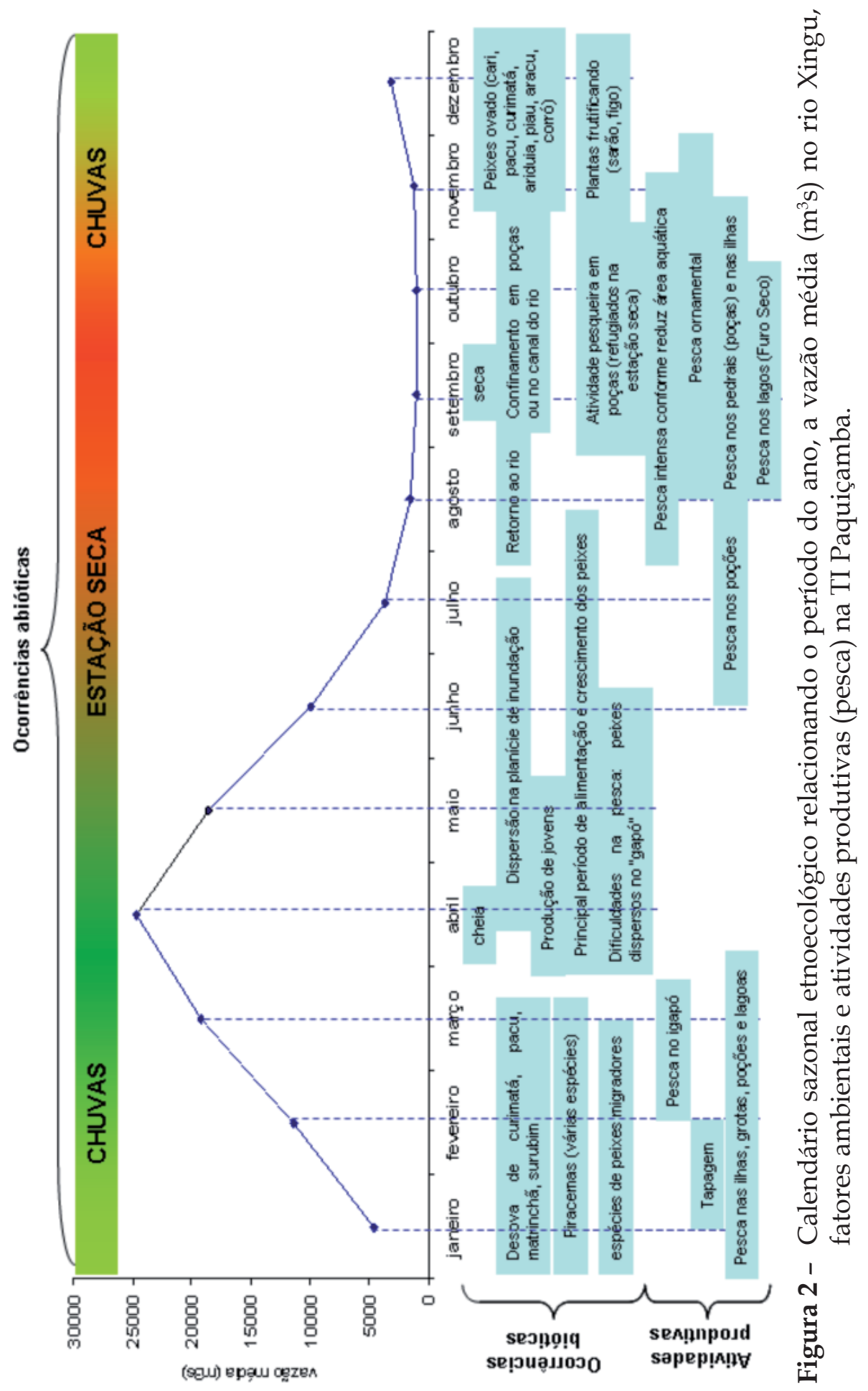

142 Jaime R. CARVALHO JR.; Maria de J. da C. FONSECA; André R. de SANTANA; Luiza NAKAYAMA. O conhecimento etnoecológico dos pescadores yudjá, Terra Indígena... 


\section{Considerações finais}

O conjunto de informações etnoecológicas que os pescadores yudjá possuem é dinâmico e envolve pesquisa, experimentação, observação, raciocínio, especulação e intuição. Além da transmissão cultural entre gerações, muito conhecimento aperfeiçoa-se em uma mesma geração, por meio das conversas e das interações do cotidiano.

Em vista de a pesca ser a principal fonte para subsistência e/ou comercialização, os Yudjá têm um patrimônio rico em detalhes e, na maioria das vezes, concordantes com observações científicas. Tal patrimônio teóricoprático compartilhado, que os pescadores apresentam sobre comportamento, hábitos alimentares, reprodução e ecologia dos peixes, amplia o conhecimento sobre o ambiente, território e seus recursos naturais. Assim, concluímos que a sobrevivência biológica e cultural dos Yudjá tem conexões estreitas com componentes bióticos e abióticos existentes na região da VGX.

Os saberes, dizeres e fazeres foram visualizados com maior detalhamento a partir do uso do mapa conceitual, mostrando a sua validade como técnica de pesquisa e como instrumento indispensável para construção dos conhecimentos sobre pesca no cotidiano indígena.

Portanto todo esse conhecimento construído na lida diária, em contato direto com o rio Xingu, por estarem embasados na realidade local, deve ser usado como subsídio para programas e ou projetos ambientais e de conservação e manejo.

Nesse sentido, os resultados do presente estudo foram o insight para a elaboração do "Projeto Yudjá: a pesca e piscicultura itinerante para os indígenas da VGX", concebido em módulos e com duração de, no mínimo, quatro anos, em virtude da necessidade de capacitação teórico-prática dos pescadores.

Os conteúdos dos módulos propõem troca de informações a respeito da importância da biodiversidade de peixes existentes nos diversos cursos hídricos da TI Paquiçamba e suas características biológicas, tais como hábitos alimentares e reprodutivos, com a finalidade de promover a seleção de espécies de peixes nativas, levando em consideração a preferência alimentar da comunidade yudjá e a viabilidade de criação das espécies selecionadas, considerando-se os saberes, fazeres e dizeres da referida comunidade.

Nesse aspecto, está prevista, no projeto, a participação de técnicos na área de pesca e de lideranças pesqueiras, para ministrarem palestras relativas aos conhecimentos básicos de infraestrutura e técnicas de construção de pequenas represas e tanques; de manejo para qualidade de água, usando plantas filtradoras; de aquisição de materiais de manejo e segurança individual e coletiva. Esses conhecimentos técnicos auxiliarão a fabricação de equipamentos simples, com materiais encontrados na natureza, facilitando, assim, a lida diária 
dos Yudjá. Também estão contempladas a aprendizagem de noções sobre os vários alimentos, que podem ser aproveitados pelos peixes da TI Paquiçamba e as estratégias de produção para aumentar a disponibilidade de alimentos naturais nos ambientes aquáticos de criação.

Como os pescadores yudjá trabalham, na maioria das vezes, sozinhos ou com seus familiares, outro conteúdo que integra os módulos diz respeito aos conceitos de associativismo e às técnicas de boas práticas de despescas, manipulação e conservação do pescado, através do uso redes, gelo e salga, os quais serão amplamente discutidos e trabalhados com a comunidade de pescadores. Também estão incorporadas, nos módulos, questões sobre manutenção dos canais de abastecimento e escoamento da estrutura da represa e tanques, no caso da piscicultura, e sobre medidas preventivas em relação ao lixo e aos resíduos sólidos jogados nos cursos hídricos, os quais comprometem a qualidade da água e refletem na saúde dos peixes e da comunidade indígena.

Em vista de várias espécies de peixe identificadas na VGX serem herbívoras, também é prevista a discussão sobre o incentivo ao reflorestamento, através de um Sistema Agroflorestal-Aquícola no entorno dos cursos hídricos, com espécies florestais e frutíferas de uso alimentar dos peixes, pois constituiriam uma excelente fonte de opção de alimentos exógenos (frutos, sementes, folhas, raízes, insetos, aranhas, dentre outros), em conjunto com a implantação de roças tradicionais para suprir a alimentação dos peixes com a finalidade de minimizar os custos de produção.

Pensamos também, permeando os módulos, dialogar com os participantes sobre assuntos cotidianos referentes à Educação Ambiental, baseados em Fonseca e Nakayama (2010).

A perspectiva da ação educativa proposta é que os participantes do projeto coloquem em prática os conhecimentos adquiridos, qualificando o manejo cotidiano da produção de peixes da TI Paquiçamba. Espera-se, ain$\mathrm{da}$, que alguns desses pescadores se tornem agentes multiplicadores desses saberes, dizeres e fazeres.

Entretanto cabe lembrar que esta ação educativa está apenas no papel, mas consubstanciada nos resultados da pesquisa que compõem este texto. Nossa expectativa é que tenhamos recursos financeiros para a implantação, considerando os impactos da construção da UHE Belo Monte na região.

\section{Agradecimentos}

A Kirsten Barrett, do Alaska Science Center, pela versão do resumo para o inglês; a FAPESPA, pela concessão da bolsa de doutorado ao primeiro autor; aos moradores da comunidade indígena Juruna da TI Paquiçamba, pela contri- 
buição para a pesquisa, mediante suas histórias de vida, narrativas, respostas aos roteiros de perguntas e pela oportunidade do aprendizado vivenciado; e a toda a equipe EIA-RIMA UHE Belo Monte estudo socioambiental componente indígena: Terra Indígena Paquiçamba, principalmente a Maria Elisa Guedes Vieira (coordenadora Antropóloga), por toda orientação e apoio em nossas atividades dentro e fora da aldeia.

\section{Referências}

AB'SÁBER, Aziz Nacib. A Amazônia: do discurso à práxis. São Paulo: EDUSP, 1996. BERNA, Vilmar Demamam. Pensamento ecológico: reflexão crítica sobre meio ambiente, desenvolvimento sustentável e responsabilidade social. São Paulo: Paulinas, 2005.

BUCKUP, Paulo Andreas; MENEZES FILHO, Naercio Aquino; GHAZZI, Mirian Sant'anna (Eds.). Catálogo das espécies de peixes de água doce do Brasil. Rio de Janeiro: Museu Nacional, 2007. (Série livros, 23).

CARVALHO Jr., Jaime Ribeiro; CARVALHO, Nigiacy Alcidia Seabra da Silva; NUNES, José Leocyvan Gomes; CAMÕES, Andrew; BEZERRA, Márcia Francineli da Cunha; SANTANA, André Ribeiro de; NAKAYAMA, Luiza. Sobre a pesca de peixes ornamentais por comunidades do rio Xingu, Pará - Brasil: relato de caso. Boletim do Instituto de Pesca, São Paulo, v. 35, n. 3, p. 521-530, 2009.

CASTRO, Edna. Território, biodiversidade e saberes de populações tradicionais. In: CASTRO, Edna; PINTON, Florence (Orgs.). Faces do trópico úmido: conceitos e questões sobre desenvolvimento e meio ambiente. Belém: Cejup, 1997.

DANTAS, Osmarina Maria dos Santos; NAKAYAMA, Luiza; SANTANA, André Ribeiro de. Abordagens de ambiente na ótica de professores de Ciências. Revista Brasileira de Educação Ambiental, Cuiabá, n. 4, p. 107-114, 2009.

DIEGUES, Antonio Carlos Sant'Ana. Pescadores, camponeses e trabalhadores do mar. São Paulo: Ática, 1983.

ESCHMEYER, William (Ed.). Catalog of fishes. San Francisco: California Academy of Sciences, 1988. v. 3, 2905p.

FARGETTI, Cristina Martins. Yudjá Kariá: Festa Juruna. Folheto XVIII Moitará, Exposição/Feira de Artesanato Indígena. FUNAI, 1997.

FERNANDES-PINTO, Érika; MARQUES, José Geraldo W. Conhecimento Etnoecológico de pescadores artesanais de Guaraqueçaba (PR). In: DIEGUES, Antonio Carlos (Org.). Enciclopédia Caiçara 1: O olhar do pesquisador. São Paulo: HUCITEC, NUPAUB/CEC, 2004. p. 163-190.

FONSECA, Maria de Jesus da Conceição Ferreira; NAKAYAMA, Luiza. Narrativas para ensinar-aprender a Amazônia: uma contribuição à Educação Ambiental em contextos educacionais diversos. Revista de Estudos Universitários, Sorocaba, v. 36, n. 3, p. 143-153, 2010. 
FURTADO, Lourdes Gonçalves. Origens pluriétnicas no cotidiano da pesca na Amazônia: contribuições para projeto de estudo pluridisciplinar. Boletim do Museu Paraense Emílio Goëldi - Ciências Humanas, Belém, v. 1, n. 2, p. 159-172, 2006.

Os pescadores do Rio Amazonas: um estudo antropológico da pesca ribeirinha numa área Amazônica. Belém: Museu Paraense Emílio Goeldi, 1993.

. Pesca artesanal: um delineamento de sua história no Pará. Boletim do Museu Paraense Emílio Goëldi - Antropologia, Belém, n. 79, p. 1-50, 1981.

JARDIM, Sérgio Brião. Mapas cognitivos: um caminho para construir estratégias. S.d. Disponível em: <artigocientifico.tebas.kinghost.net/.../artc_1147098746_78.pdf>. Acesso em: $10 \mathrm{dez} .2010$.

LOUREIRO, Violeta Refkalefsky. Amazônia: estado, homem, natureza. Belém: Cejup, 1992.

MARQUES, José Geraldo W. Pescando pescadores: Ciência e Etnociência em uma perspectiva ecológica. 2. ed. São Paulo: NUPAUB/USP, 2001.

McCURDY, David W.;SPRADLEY, James P.;SHANDY, Dianna J. The cultural experience: Ethnography in complex society. 2. ed. Tennessee: Kingsport Press of Kingsport, 2004.

MEGGERS, Betty. Amazônia: a ilusão de um paraíso. Rio de Janeiro: Civilização Brasileira, 1977.

MINAYO, Maria Cecília de Sousa (Org.). Pesquisa social: teoria, método e criatividade. 20. ed. Petrópolis: Vozes, 2002.

MORAES, Bergson Cavalcanti de; COSTA, José Maria Nogueira da; COSTA, Antonio Carlos Lôla da; COSTA, Marcos Heil. Variação espacial e temporal da precipitação no Estado do Pará. Acta Amazônica, Manaus, v. 35, n. 2, p. 207-214, 2005.

POSEY, Darrell. Conseqüências da presença do Índio Kayapó na Amazônia: recursos antropológicos e direitos de recursos tradicionais. In: CAVALCANTI, Clóvis (Org.). Desenvolvimento e natureza: estudos para uma sociedade sustentável. 3. ed. São Paulo: Cortez; Recife: Fundação Joaquim Nabuco, 2001.

REIGOTA, Marcos Antonio dos Santos. Meio ambiente e representação social. 6. ed. São Paulo: Cortez, 2004.

REIS, Roberto; KULLANDER, Sven; FERRARIS, Carl. Check list of the freshwater fishes of South and Central America. Porto Alegre: EDIPUCRS, 2003.

RIBEIRO, Felipe de Azevedo Silva; CARVALHO Jr., Jaime Ribeiro; FERNANDES, João Batista Kochenborger; NAKAYAMA, Luiza. Comércio brasileiro de peixes ornamentais. Panorama da Aquicultura, Rio de Janeiro, v. 111, p. 54-59, 2008.

. Cadeia produtiva do peixe ornamental. Panorama da Aquicultura, Rio de Janeiro, v. 112, p. 1-10, 2009.

SANTANA, André Ribeiro de. O ambiente sob o olhar de estudantes em diferentes momentos de escolarização. 2004. Dissertação (Mestrado em Ciências e Matemáticas) - PPGCM/ Universidade Federal do Pará, Belém, 2004.

146 Jaime R. CARVALHO JR.; Maria de J. da C. FONSECA; André R. de SANTANA; Luiza NAKAYAMA. O conhecimento etnoecológico dos pescadores yudjá, Terra Indígena... 
SANTOS, Geraldo Mendes dos; SANTOS, Ana Carolina Mendes dos. Sustentabilidade da pesca na Amazônia. Estudos Avançados, São Paulo, v. 19, n. 54, p. 165-182, 2005.

SANTOS, Vívian Ribeiro; SANTANA, André Ribeiro de; NAKAYAMA, Luiza. Percepção ambiental: avaliação do perfil de cidadania ambiental dos estudantes dos cursos de licenciatura do Instituto Federal de Educação, Ciência e Tecnologia do Pará (IFPA). Educação Ambiental em Ação, Novo Hamburgo, n. 31, p. 1-12, 2010.

SARAIVA, Márcia Pires. Sob o signo da identidade: os índios Juruna da TI Paquiçamba e a ameaça da UHE Belo Monte. Paper do NAEA, Belém, n. 183, p. 1-20, 2005.

. Identidade multifacetada: a reconstrução do "ser indígena" entre os Juruna do médio Xingu. Belém: NAEA/UFPA, 2007a.

Os Juruna citadinos: História, memória e identidade em Altamira do Pará. Publicação do CEPE, Abaetetuba, n. 1, p. 1-25, 2007b.

SAUVÉ, Lucie. Éducacion relative à l'environnement: une diversité de conceptions. In: SAUVÉ, Lucie. Pour une éducacion relative à l'environnement. Montreal: Guérin, 1994.

. Educação ambiental e desenvolvimento sustentável: uma análise complexa. s.d. Disponível em: <HTTP://www.ufmt.br/revista/arquivo/rev10/educacao_ ambiental_e_desenvolvim.html>. Acesso em: 20 dez. 2010.

SILVA, Francilda Sousa; OLIVEIRA, Gislene Miranda de; SILVA, Leiliam Jorge da; CONCEIÇÃO, Letícia Carneiro da; NAKAYAMA, Luiza; SANTANA, André Ribeiro de. Educação Ambiental: olhares e propostas no município de Rondon do Pará. Revista Eletrônica do Mestrado em Educação Ambiental, Rio Grande, v. 24, p. 1-11, 2010.

SOUSA Jr., Wilson Cabral de; REID, John; LEITÃO, Neidja Cristine Silvestre. Custos e benefícios do Complexo Hidrelétrico Belo Monte: uma abordagem econômico-ambiental. Lagoa Santa: Conservation Strategy Fund/CSF Brasil, 2005.

THÉ, Ana Paula Glinfskoi. Etnoecologia e produção pesqueira dos pescadores da Represa de Três Marias (MG). 1999. Dissertação (Mestrado em Ecologia e Recursos Naturais) PPGERN/Universidade Estadual Paulista “Júlio de Mesquita Filho”, São Carlos, 1999.

VIEIRA, Maria Elisa Guedes; SILVA, Claudio Emidio; LIMA, Flávia Pires Nogueira; CARVALHO Jr., Jaime Ribeiro; PIMENTEL, Noara Modesto. EIA-RIMA AHE Belo Monte estudo socioambiental componente indígena: Terra Indígena Paquiçamba. Relatório Técnico-Científico, 2009.

\section{Recebido em 13 de maio de 2011}

Aprovado para publicação em 4 de agosto de 2011 
